\title{
OnabotulinumtoxinA for the treatment of headache: an updated review
}

\author{
Joseph H. Talbet ${ }^{1}$, Ayman C. Elnahry ${ }^{2}, *$ (1) \\ ${ }^{1}$ College of Medicine, Howard University, 20059 Washington, D.C., USA \\ ${ }^{2}$ Department of Ophthalmology, Faculty of Medicine, Cairo University, 11956 Cairo, Egypt \\ *Correspondence: ayman_elnahri@cu.edu.eg (Ayman C. Elnahry) \\ DOI:10.31083/j.jin2101037 \\ This is an open access article under the CC BY 4.0 license (https://creativecommons.org/licenses/by/4.0/). \\ Submitted: 24 June 2021 Revised: 6 August 2021 Accepted: 25 August 2021 Published: 28 January 2022
}

Botulinum toxin (BT) is a neurotoxin produced by Clostridium botulinum, a gram-positive anaerobic bacterium. Systemic human intoxication from BT following oral ingestion results in acute and lifethreatening muscle paralysis called botulism. BT has a wide scope of therapeutic uses, including conditions associated with increased muscle tone, smooth muscle hyperactivity, salivation, sweating, and allergies, as well as for cosmetic purposes. Several commercial forms of BT are available for medical use, including Botox (onabotulinumtoxinA). Multiple studies have found evidence of an analgesic effect of onabotulinumtoxinA and demonstrated the benefits of its use for the treatment of various chronic pain disorders. In this review, we provide an update on the use of onabotulinumtoxinA for the treatment of headache disorders.

\section{Keywords}

Botulinum toxin; Chronic headache; Chronic migraine; Cluster headache; OnabotulinumtoxinA; Neurotoxin

\section{Introduction}

Botulinum toxin (BT) is one of the most powerful toxins encountered in nature. It is a neurotoxin protein produced by Clostridium botulinum, a gram-positive anaerobic bacterium [1]. Chemically, BT is comprised of two polypeptide chains joined by a disulfide bond. Seven antigenically distinct serotypes (A to $G$ ) have been identified so far, with types $A$ and $B$ able to cause disease in humans $[1,2]$. Oral ingestion of BT leads to systemic human intoxication and produces acute and life-threatening muscle paralysis known as botulism [3]. BT causes dose-dependent, reversible muscle relaxation by blocking the release of acetylcholine from nerve endings at the neuromuscular junction [4]. Consequently, BT has been observed to have a wide range of therapeutic uses, including disorders associated with increased muscle tone, smooth muscle hyperactivity, sweating, salivation, allergies and pain, and for cosmetic purposes [5]. Several commercial forms of BT are offered for medical applications, including Botox (onabotulinumtoxinA, Allergan Inc., Irvine, CA, USA), Dysport/Azzalure (abobotulimumtoxinA, Ipsen, Slough, UK/Galderma, Paris, France), Xeomin/Bocouture (incobotulinumtoxinA, Merz Pharma- ceuticals GmbH, Frankfurt, Germany), and Jeuveau (prabotulinumtoxinA, Evolus Inc., Newport beach, CA, USA) [16]. Here, we review the use of onabotulinumtoxinA for the treatment of various types of headaches.

\section{Literature search}

PubMed and OVID MEDLINE were searched on 24 April 2021, using the following terms: botulinum toxin, botox, onabotulinumtoxin $\mathrm{A}$, headache, migraine, tension type headache, cluster headache, cervicogenic headache, post-traumatic headache, and low-tension headache. There were no date restrictions applied and all study types were included. References contained within the included publications were also searched to identify additional relevant studies.

\section{Onabotulinumtoxin A and headaches}

Clinical studies have suggested an analgesic effect of BT and various benefits for the treatment of chronic pain, including headache disorders [6]. Headache is the most common nervous system disorder. It has a variety of causes and negatively affects the quality of life in people of all ages [7]. Headaches are classified as primary or secondary types. The former are those that arise without any signs of an underlying organic disease. Primary headaches are further subclassified into tension-type headaches, migraine, trigeminal autonomic cephalalgia, and other less common forms such as new daily persistent headache and nummular headache [8]. The International Headache Society diagnostic criteria for headache disorders (Third International Classification of Headache Disorders) defines primary headache disorders as those in which the headache itself is the disease. Headache disorders can be further classified into episodic or chronic according to their frequency of occurrence [9].

The Food and Drug Administration (FDA) approved BT under the product name Oculinum (onabotulinumtoxin A, Allergan Inc., Irvine, CA, USA) for treatment of blepharospasm in 1989 [10]. BT injections were first proposed as an effective treatment for headaches when it was found 
incidentally that individuals who suffered from chronic headaches experienced an improvement following cosmetic BT injections [11, 12]. During the 1990s, interest grew for the treatment of tension-type headache with BT due to its muscle-paralyzing actions. Oculinum was later renamed Botox, and a long-term clinical trial program was launched to test BT type A for the treatment of headaches. Subsequent studies reported benefits from the use of onabotulinumtoxin A to treat migraine. In 2002, several headache experts indicated that onabotulinumtoxinA was safe and effective for prophylactic and acute treatment of migraine [13]. In 2010, the United States FDA approved Botox ${ }^{\circledR}$ for the treatment of chronic migraine. In 2016, the American Academy of Neurology recommended onabotulinumtoxin $A$ as a treatment option for chronic migraine patients [14]. Currently, onabotulinumtoxinA for the treatment of headache is only regulated and approved for patients with chronic migraine. Its use for other subtypes of headache is considered to be offlabel treatment.

Chronic daily headache is a heterogeneous group of headache symptoms with a frequency of more than 15 days per month, and which persists for longer than three months [15]. The four common subtypes are chronic migraine, chronic tension-type headache, new daily persistent headache, and hemicrania continua [16]. The estimated prevalence in the general population of this disabling neurological condition is about $4 \%$ to $5 \%$ and it is known to have a significant negative impact on daily living and on the quality of life $[16,17]$.

\subsection{OnabotulinumtoxinA and chronic migraine}

Chronic migraine is defined as the occurrence of 15 or more headache days per month for longer than a threemonth period, with at least 8 days per month showing features of migraine [18]. Approximately one-third of chronic headaches are classified as chronic migraine [19]. However, chronic migraine varies amongst patients in terms of the intensity of pain, the frequency of days with headache, allodynia, and the overall migraine-related disability [20]. Although various pharmacological treatment options are used as prophylaxis for chronic migraine, a significant proportion of patients still suffer from recurrent attacks. This has led some experts to favor surgical intervention for the treatment of chronic headaches [21]. Numerous studies have therefore been carried out to find a more efficient way to control pain in chronic headache conditions, with BT having shown good results in this context.

The FDA has approved intramuscular injection of onabotulinumtoxin A as a preventive treatment for chronic migraine headaches. Although some experts believe that extra muscular injections are just as effective as intramuscular injections, there are no peer-reviewed studies to support this contention [22]. OnabotulinumtoxinA is therefore administered to the scalp, since migraine pain is believed to come from the meninges, as well as to the forehead, bridge of the nose, the temples, the back of the head, and neck (Figs. 1,2)
$[21,23]$. Some studies have suggested that the optimal injection points for onabotulinumtoxin $A$ in the treatment of chronic migraine are in the temporal region and that it should be administered $>45 \mathrm{~mm}$ above the zygomatic arch to avoid injection into the tendon $[24,25]$. The greater occipital nerve is derived primarily from the $\mathrm{C} 2$ dorsal root and is the major sensory nerve in the occipital area. The blocking of this nerve is a common method used to treat various headaches, especially occipital headaches [26]. Several studies on ultrasoundguided greater occipital nerve block using onabotulinumtoxin A have shown effectiveness in lowering both short- and long-term pain in patients with chronic headache in the occipital area.

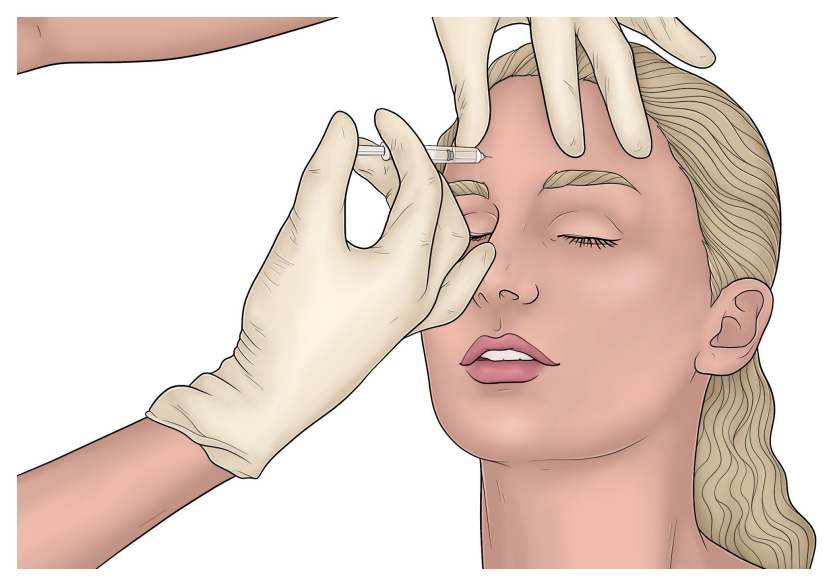

Fig. 1. Botulinum toxin injection to the forehead for the treatment of chronic migraine.

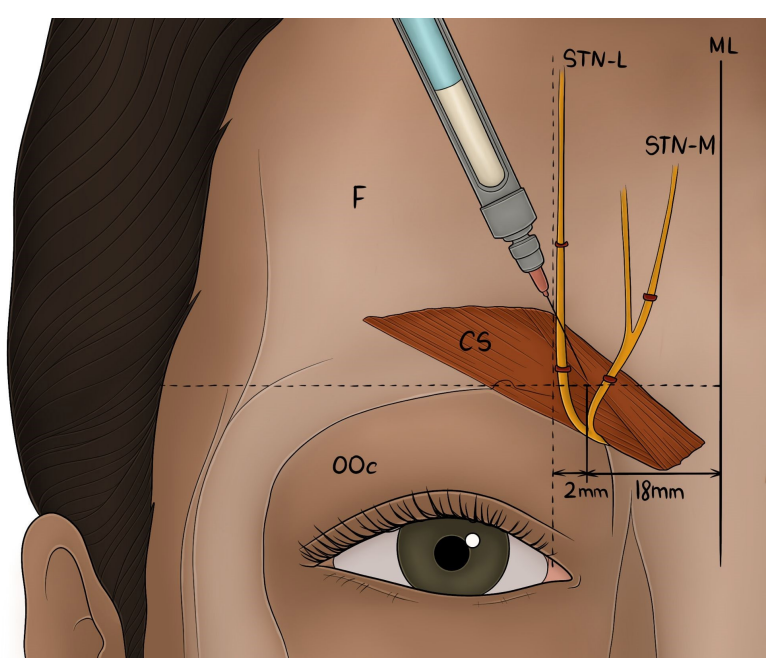

Fig. 2. Botulinum toxin injection to the bridge of the nose in the corrugator supercilli muscle for the treatment of chronic migraine. The injection is performed between the medial and lateral branches of the STN, about $18 \mathrm{~mm}$ lateral to the facial midline at the level of the supraorbital margin. F, frontalis muscle; OOC, orbicularis oculi muscle; CS, corrugator supercilii; ML, facial midline; STN-L, lateral branch of the supratrochlear nerve; STN-M, medial branch of the supratrochlear nerve. 
The Phase III Research Evaluating Migraine Prophylaxis Therapy (PREEMPT) program consisted of two phase III randomized controlled multicenter trials (PREEMPT 1 and 2) that evaluated the effectiveness of onabotulinumtoxin $A$ in patients with chronic migraine [27-29]. All patients in these trials received intramuscular injections of onabotulinumtoxin $A$ at 31 injection sites in 7 head and neck muscles with a fixed-site and fixed-dose injection paradigm (5 U in $0.1 \mathrm{~mL}$ per injection). In addition, up to 40 units of onabotulinumtoxin A could be administered at 8 other injection sites as needed across three head and neck muscles with a "followthe-pain" approach. This standardized treatment program is known as the PREEMPT injection paradigm [27]. The PREEMPT studies found marked improvement in several headache symptoms and showed that treatment was associated with improved patient functioning, vitality and overall quality of life, as well as reduced psychological distress.

How onabotulinumtoxinA reduces the frequency and intensity of migraine headaches remains to be determined [8]. The clinical impact of onabotulinumtoxinA on migraine is observed within the first day of injection and is much faster than the 5 or more days needed to observe clinical effects of onabotulinumtoxinA at the neuromuscular junction [30]. After the injection of onabotulinumtoxinA into the extracellular space, the heavy chain of this neurotoxin binds to receptors on the nerve terminals of C-fibers. It is then endocytosed and enters the nerve terminals inside enclosed vesicles. The light chain of the neurotoxin then dissociates from the heavy chain and enters the cell cytoplasm where it cleaves a critical protein (the synaptosomal-associated protein) necessary for fusion of neuropeptide-bearing vesicles with nerve terminal membranes, thus preventing neuropeptide release. Upon activation by stimuli, the sensory nerve endings of Cfibers in the meninges release neuropeptides. The role of onabotulinumtoxin A in blocking the release of these neuropeptides from peripheral C-fiber nerve endings is most likely the key mechanism that underlies its therapeutic action against chronic migraine [13].

Recent clinical studies have consistently shown onabotulinumtoxinA to be effective in preventing chronic migraine by reducing the frequency of headaches and their duration or intensity, and hence their functional and severity impact, including when administered in a targeted fashion [3134]. Many studies have confirmed the higher tolerability and cost-effectiveness of onabotulinumtoxinA treatment for chronic migraine $[24,31,34,35]$. Furthermore, the REPOSE study on onabotulinumtoxinA treatment for chronic migraine found lower use of healthcare resources and related costs using the PREEMPT injection paradigm [36]. Targeted therapy may result in even better, more cost effective, and longer-term results [32, 34]. Botox was also recently found to be cost-effective for the treatment of chronic migraine in Norway and Sweden [37]. OnabotulinumtoxinA was also found to improve migraine-related disability by reducing the intensity and frequency of headache pain in patients with chronic migraine [38]. In another recent multicenter study of chronic migraine, early treatment with onabotulinumtoxinA was more likely to be associated with a sustained clinical response [39]. In the COMPEL study, treatment with onabotulinumtoxinA also led to improvements in disability and quality of life measures in daily headache, but a longer period of treatment was needed [40]. OnabotulinutoxinA was also shown to be effective and safe in patients with allodynia [41]. Additional benefits of treatment with this agent may include an improved response to acute treatment and reduced drug intake [42-44]. Well-controlled clinical trials have shown that patients with overuse of headache medication can be treated successfully with onabotulinumtoxinA and topiramate [45]. Comparative studies have shown that onabotulinumtoxin $\mathrm{A}$ is an effective and safe alternative for the treatment of chronic migraine in patients who discontinue topiramate treatment and can be started during the tapering of topiramate [46, 47]. It should be noted however that combining classic migraine therapy with onabotulinumtoxinA injection should be avoided in order to allow a better understanding of the efficacy of each treatment in the individual patient.

It is well known that psychiatric comorbidities including depression and anxiety are more common in patients with chronic migraine [48]. A study of patients suffering chronic daily headaches with comorbid anxiety and depression found that onabotulinumtoxinA treatment may be an effective and safe intervention in such cases [16]. OnabotulinumtoxinA was well tolerated in chronic migraine patients with comorbid depression and reduced the frequency, impact and associated disability of headaches, leading to significant improvement in the symptoms of anxiety and depression [49]. Furthermore, a study on chronic migraine patients with impulse use disorders and medication overuse found that onabotulinumtoxinA injections improved anxiety symptomatology and impulse control disorders [50].

BT in doses used for upper-face cosmetic purposes may also be helpful for the treatment of certain subtypes of migraine. In a study that evaluated the effect of Botox injections for cosmetic purposes on migraine subtypes, more improvement in headache frequency was observed in patients with imploding and ocular migraine in comparison to patients with exploding migraine [51]. This suggests that Botox doses used for cosmetic applications may be sufficient for the prevention of some types of migraine attacks.

A small study in adolescents on onabotulinumtoxinA treatment for chronic daily headaches found that all patients experienced a decrease in headache frequency and in pain intensity immediately following injection. Some cases quickly returned to regular school attendance, thus highlighting the ability of this treatment in allowing patients to resume their regular daily activities [15]. A study conducted in a large pediatric headache center reported on a possible reversal of the underlying pathology when onabotulinumtoxin A was given as an adjunct to other preventive therapies, even when the 
disease was at its peak [52]. OnabotulinumtoxinA injections were also found to be safe during pregnancy, with no reported adverse effects on pregnancy outcomes [53].

Many patients with chronic migraine have a high intake of pharmacological agents for relief from headaches as well as prophylaxis. It has been estimated that more than half of cases with chronic migraine who consult in headache clinics suffer from excessive use of analgesics [54]. This overuse of medication can lead to the development of headaches (medication overuse headache). A study on the use of onabotulinumtoxinA in patients with medication overuse headache showed positive results with different dose regimes [55]. Another recent study on prophylactic treatment with onabotulinumtoxinA for medication overuse headache showed that 12 weeks of therapy can significantly reduce the consumption of acute analgesics and the overall number of days with headache. The use of analgesics without serious side effects is vitally important to reduce chronic disability associated with migraine, to increase patient quality of life, and to reduce spending on health resources [56]. Another study on prophylactic treatment with onabotulinumtoxinA for medication overuse headache found that its efficacy and safety lasted for up to 3 years. This raises the possibility of long-term treatment with onabotulinumtoxinA to prevent chronic migraine [57].

In conclusion, recent clinical trials have repeatedly shown excellent benefit from onabotulinumtoxinA treatment for chronic migraine in various age groups. Therefore, the logical next question is to ask whether onabotulinumtoxin $\mathrm{A}$ is also beneficial for the treatment of other types of headaches.

\subsection{OnabotulinumtoxinA and episodic migraine}

Episodic migraine is defined as $0-14$ headache days per month, in contrast to chronic migraine which is characterized by 15 or more headache days per month [58]. A study of patients with episodic migraine (mostly $<8$ headache days per month) treated with onabotulinumtoxinA found that those with a low baseline frequency were more likely to experience complete responsiveness [59]. Another study that investigated onabotulinumtoxin A treatment for episodic migraine (approximately 5 headache days per month and 1.5 days mean duration of headache) found that treated subjects experienced fewer migraines of any severity [60]. These authors also reported fewer days with migraine needing treatments, less severe attacks and reduced frequency of vomiting, together with satisfactory safety profile and good tolerability. A randomized, double-blind trial of onabotulinumtoxin A for episodic migraine found more improvement in headache frequency in the Botox group compared to the placebo group at day 180 [61]. Multiple treatments with Botox proved safe and well tolerated. However, several recent studies and a metaanalysis of clinical trials for episodic migraine found no association between onabotulinumtoxin $\mathrm{A}$ treatment and clinical outcome [62-67].

\subsection{OnabotulinumtoxinA and tension-type headache}

Tension-type headache is the most frequent chronic recurring head pain. It occurs more frequently in women than men and has a lifetime prevalence of $30 \%$ to $78 \%$ in the global population [68]. Recent research has shown that onabotulinumtoxin $A$ is effective in reducing tension-type headache intensity and is safe and well-tolerated [69]. A randomized, double-blind trial of onabotulinumtoxinA injection into specific myofascial trigger points found improvement in pain from chronic tension-type headache [70]. Therapy for facial spasms might contribute to the observed improvement for tension-type headache by reducing the stress from the muscle spasms, rather than from the reduced muscle stiffness [71]. Stress factors are also related to muscle exhaustion and to the release of acetylcholine from presynaptic nerve terminals in the peripheral pain mechanism. Because onabotulinumtoxinA needs to be given every 12 weeks, this is more convenient for most patients compared to taking daily analgesic drugs [69]. However, treatment results depend on the dose given, the site of injection, the number of cycles and the interval periods [68].

\subsection{OnabotulinumtoxinA and new daily persistent headache}

New daily persistent headache is a subtype of chronic daily headache that is challenging to treat. The 3rd edition of the International Classification of Headache Disorders classifies it as a persistent primary daily headache with a distinct and memorable onset. The pain becomes continuous and unrelenting within 24 hours and is present for $>3$ months. In a case of new daily persistent headache reported in a 67year-old male, complete response was observed following repeated injections with BT type A [72]. A retrospective study on new daily persistent headache and onabotulinumtoxin $\mathrm{A}$ therapy showed a $50.0 \%$ decrease in headache frequency at 6 months, a $63.6 \%$ decrease at 12 months, a $50.0 \%$ improvement in headache severity at 6 months, and a $77.8 \%$ improvement at 12 months [73].

\subsection{OnabotulinumtoxinA and cluster headache}

Cluster headache, also known as suicidal headache, is a well-defined primary headache disorder that can present in both episodic and chronic forms. It is a primary headache syndrome that often does not respond satisfactorily to drug therapies. Several studies on the efficacy of onabotulinumtoxin A for cluster headache have shown significant improvement in headache frequency within a week of treatment and lasting for up to 6 months [74]. A recent study showed that onabotulinumtoxinA was highly effective when used as add-on therapy in patients with refractory chronic cluster headache [75]. A prospective study on treatment of intractable chronic cluster headache with a single injection of onabotulinumtoxin A to the sphenopalatine ganglion found a significant reduction in cluster attack frequency at 24 weeks of follow up [76]. An open label, single-center study of onabotulinumtoxin A as an add-on therapy for prophylactic treatment of cluster headache found improvement in some 
but not all patients with chronic cluster headache, but no benefit in those with episodic cluster headache [77]. Cluster headache may be associated with blepharospasm, which could also benefit from treatment with BT injections [78].

\subsection{OnabotulinumtoxinA and cervicogenic headache}

Cervicogenic headache can arise from several factors associated with the back of the head and neck. Typically, cervicogenic headache starts at the rear of the head, neck and ear, and subsequently spreads to the zygomatic region. Cervicogenic headache is associated with throbbing pain and is always triggered by mechanical causes [79]. Several studies have reported benefits for onabotulinumtoxinA treatment in headaches related to the neck [23]. In a case report of a patient with a 5-year history of cervicogenic headache following whiplash injury, a dramatic response was observed after a single BT injection despite being medically refractory to usual therapies [80]. The patient required repeat injections to maintain the improvement thereafter. A recent study reported significant improvement in the range of neck motion and in pain reduction at 4 weeks [79]. Compared to pre-treatment levels, BT injection significantly lowered the frequency and severity of pain at 6- and 12-week following treatment. However, a double-blind, placebo-controlled, clinical trial of onabotulinumtoxinA for the treatment of chronic whiplash syndrome found that BT was not effective against chronic neck pain [81]. Nevertheless, another double-blind, placebo-controlled, clinical trial of BT type A (Dysport) for whiplash-associated disorder did find some benefit from this form of treatment [82].

\subsection{OnabotulinumtoxinA and post-traumatic headache}

Traumatic brain injury and post-traumatic headache associated with this injury negatively impact the lives of patients and their families [83]. As originally defined in the third edition of the International Classification of Headache Disorders, post-traumatic headache begins within 7 days of a mild, moderate, or severe traumatic brain injury and continues for longer than 3 months [83]. In a study of military veterans, onabotulinumtoxinA was shown to improve the frequency and intensity of post-traumatic headache when compared to placebo [83]. In another study of active-duty military patients, onabotulinumtoxinA was beneficial for the treatment of headaches related to concussion [84]. Moreover, a case study of onabotulinumtoxinA for the treatment of post-traumatic headache showed complete absence of pain, even after 5 years with this condition [85]. Bruxism is a rhythmic grinding of teeth that can sometimes occur following traumatic brain injury and lead to headache. This condition was also successfully treated with BT type A injection [86].

\subsection{OnabotulinumtoxinA and chronic post-craniotomy headache}

Chronic post-craniotomy headache is localized pain over the surgical site experienced by the majority of patients with craniotomy. Some patients describe it as a mild to moderate sensation of pressure involving the entire head and being more severe at the surgical site, and/or a throbbing sensation that can be accompanied by nausea and vomiting [87]. A study on peri-incisional onabotulinumtoxinA for chronic post-craniotomy headache following traumatic brain injury concluded that onabotulinumtoxinA injections may be useful for the treatment of chronic peri-incisional head pain after remote craniotomy and without any serious adverse effects. Furthermore, onabotulinumtoxinA appears to have several important benefits over current oral analgesics for the treatment of chronic post-craniotomy headaches. Based on a recent case series, patients can enjoy an extended period of pain relief following a single administration and without experiencing any side effects such as cognitive problems or somnolence [87]. Another case series of late-onset headache in post-temporal craniotomy patients who developed temporofacial pain due to total or partial temporal muscle hypertrophy found that onabotulinumtoxinA treatment significantly reduced pain without any adverse effects [88].

\subsection{OnabotulinumtoxinA and low-tension headache}

Diagnosis of orthostatic low cerebrospinal fluid (CSF) pressure headaches due to reduced CSF volume is based on clinical presentation with at least one abnormal magnetic resonance imaging (MRI) finding, cisternography findings, or an opening pressure less than the normal value of $65 \mathrm{~mm}$ $\mathrm{H}_{2} \mathrm{O}$. A case report described significantly improved outcome following onabotulinumtoxinA injections in a patient suffering from refractory low-pressure headache. The patient continued to experience daily headaches but these were of lower intensity, suggesting that onabotulinumtoxin A may be effective for low CSF pressure headaches [89].

\subsection{OnabotulinumtoxinA and nummular headache}

Nummular headache is a primary headache characterized by superficial, coin-shaped pain. A recent study of this disorder found that the number of headache days per month, including intense headache, decreased following onabotulinumtoxin $\mathrm{A}$ injection and without any serious adverse events [90].

\section{Conclusions}

BT treatment using onabotulinumtoxinA is associated with clinically significant benefits in terms of reducing headache frequency, severity, and headache-related impacts, thus improving the quality of life for many patients who suffer from various types of headache disorders [91]. Patients who take daily oral medication for headache relief will benefit from the less frequent treatment with onabotulinumtoxinA, which also shows better efficacy and safety compared to the currently used pharmacological drugs.

\section{Author contributions}

JHT and AGE designed the research study. JHT searched the literature and wrote the manuscript draft. AGE searched the literature and edited the manuscript. Both authors read and approved the final manuscript. 


\section{Ethics approval and consent to participate}

This report was approved by Cairo University research ethics committee and followed the tenets of the Declaration of Helsinki.

\section{Acknowledgment}

The authors would like to thank The Illustrated Book of Medicine, LLC for their assistance in creating the figures.

\section{Funding}

This research received no external funding.

\section{Conflict of interest}

The authors declare no conflict of interest.

\section{References}

[1] Ashkenazi A, Blumenfeld A. OnabotulinumtoxinA for the Treatment of Headache. Headache. 2013; 53: 54-61.

[2] Silberstein SD. The Use of Botulinum Toxin in the Management of Headache Disorders. Seminars in Neurology. 2016; 36: 92-98.

[3] Dhaked RK, Singh MK, Singh P, Gupta P. Botulinum toxin: bioweapon \& magic drug. The Indian Journal of Medical Research. 2010; 132: 489-503

[4] Nigam PK, Nigam A. Botulinum toxin. Indian Journal of Dermatology. 2010; 55: 8-14.

[5] Awan KH. The therapeutic usage of botulinum toxin (Botox) in non-cosmetic head and neck conditions-an evidence based review. Saudi Pharmaceutical Journal. 2017; 25: 18-24.

[6] Sandrini G, De Icco R, Tassorelli C, Smania N, Tamburin S. Botulinum neurotoxin type a for the treatment of pain: not just in migraine and trigeminal neuralgia. The Journal of Headache and Pain. 2017; 18: 38.

[7] Ahmed F. Headache disorders: differentiating and managing the common subtypes. British Journal of Pain. 2012; 6: 124-132.

[8] Saltvig I, Matzen SH. Incidental Treatment of a Subclinical Chronic Tension-Type Headache by Cosmetic Use of Botulinum Toxin a: a Case Report. Case Reports in Dermatology. 2017; 9: 249-253.

[9] Headache Classification Committee of the International Headache Society (IHS). The International Classification of Headache Disorders, 3rd edition (beta version). Cephalalgia.2013; 33: 629-808.

[10] Finkel AG. Botulinum Toxin and the Treatment of Headache: a Clinical Review. Headache. 2011; 51: 1565-1572.

[11] Bendtsen L, Sacco S, Ashina M, Mitsikostas D, Ahmed F, PozoRosich $\mathrm{P}$, et al. Guideline on the use of onabotulinumtoxin $\mathrm{A}$ in chronic migraine: a consensus statement from the European Headache Federation. The Journal of Headache and Pain. 2018; 19: 91.

[12] Goldman ND, Dorton LH, Marcum KK, Gilbert RM, Sandoval LF. Evaluation of headache relief with cosmetic onabotulinumtoxinA injections. Journal of Cosmetic Dermatology. 2014; 13: 224-231.

[13] Becker WJ. Botulinum Toxin in the Treatment of Headache. Toxins. 2020; 12: 803.

[14] Escher CM, Paracka L, Dressler D, Kollewe K. Botulinum toxin in the management of chronic migraine: clinical evidence and experience. Therapeutic Advances in Neurological Disorders. 2017; 10: $127-135$.

[15] Schroeder AS, Huss K, Blaschek A, Koerte IK, Zeycan B, Roser T, et al. Ten-year follow-up in a case series of integrative botulinum toxin intervention in adolescents with chronic daily headache and associated muscle pain. Neuropediatrics. 2012; 43: 339-345.

[16] Zhang H, Zhang H, Wei Y, Lian Y, Chen Y, Zheng Y. Treatment of chronic daily headache with comorbid anxiety and depression using botulinum toxin a: a prospective pilot study. International Journal of Neuroscience. 2017; 127: 285-290.
[17] Hepp Z, Rosen NL, Gillard PG, Varon SF, Mathew N, Dodick DW. Comparative effectiveness of onabotulinumtoxinA versus oral migraine prophylactic medications on headache-related resource utilization in the management of chronic migraine: Retrospective analysis of a us-based insurance claims database. Cephalalgia. 2016; 36: 862-874.

[18] Hollier-Hann G, Curry A, Onishchenko K, Akehurst R, Ahmed F, Davies B, et al. Updated cost-effectiveness analysis of onabotulinumtoxin A for the prevention of headache in adults with chronic migraine who have previously received three or more preventive treatments in the UK. Journal of Medical Economics. 2020; 23: 113-123.

[19] Gandolfi M, Donisi V, Marchioretto F, Battista S, Smania N, Del Piccolo L. A Prospective Observational Cohort Study on Pharmacological Habitus, Headache-Related Disability and Psychological Profile in Patients with Chronic Migraine Undergoing Onabotulinumtoxin A Prophylactic Treatment. Toxins. 2019; 11: 504.

[20] MacGregor EA, Brandes J, Eikermann A, Giammarco R. Impact of migraine on patients and their families: the Migraine and Zolmitriptan Evaluation (MAZE) survey-Phase III. Current Medical Research and Opinion. 2004; 20: 1143-1150.

[21] Filipović B, de Ru JA, Hakim S, van de Langenberg R, Borggreven PA, Lohuis PJFM. Treatment of Frontal Secondary Headache Attributed to Supratrochlear and Supraorbital Nerve Entrapment with Oral Medication or Botulinum Toxin Type a vs Endoscopic Decompression Surgery. JAMA Facial Plastic Surgery. 2018; 20: 394-400.

[22] Wu-Fienberg Y, Ansari H, Zardouz S, Narouze S, Blaha T, Swanson $\mathrm{M}$, et al. Anatomical Look into Onabotulinumtoxin A Injection for Chronic Migraine Headache. Regional Anesthesia and Pain Medicine. 2018; 43: 869-874.

[23] Becker WJ, Chitsantikul P. Cervicogenic headache and onabotulinumtoxinA: where do we stand? Cephalalgia. 2011; 31: 979980.

[24] Choi Y, Lee W, Lee H, Lee K, Kim H, Hu K. Effective Botulinum Toxin Injection Guide for Treatment of Temporal Headache. Toxins. 2016; 8: 265.

[25] Kim YG, Bae JH, Kim H, Wang SJ, Kim ST. A Proposal for Botulinum Toxin Type A Injection Into the Temporal Region in Chronic Migraine Headache. Toxins. 2020; 12: 214.

[26] Janis JE, Hatef DA, Ducic I, Reece EM, Hamawy AH, Becker S, et al. The Anatomy of the Greater Occipital Nerve: Part II. Compression Point Topography. Plastic and Reconstructive Surgery. 2010; 126: $1563-1572$.

[27] Blumenfeld A, Silberstein SD, Dodick DW, Aurora SK, Turkel CC, Binder WJ. Method of injection of onabotulinumtoxinA for chronic migraine: a safe, well-tolerated, and effective treatment paradigm based on the PREEMPT clinical program. Headache. 2010; 50: 1406-1418.

[28] Aurora S, Dodick D, Turkel C, DeGryse R, Silberstein S, Lipton $\mathrm{R}$, et al. OnabotulinumtoxinA for treatment of chronic migraine: Results from the double-blind, randomized, placebo-controlled phase of the PREEMPT 1 trial. Cephalalgia. 2010; 30: 793-803.

[29] Diener HC, Dodick DW, Aurora SK, Turkel CC, DeGryse RE, Lipton RB, et al. OnabotulinumtoxinA for treatment of chronic migraine: results from the double-blind, randomized, placebocontrolled phase of the PREEMPT 2 trial. Cephalalgia. 2010; 30: 804-814.

[30] Gerwin R. Treatment of chronic migraine headache with onabotulinumtoxinA. Current Pain and Headache Reports. 2011; 15: 336-338.

[31] Russo M, Manzoni GC, Taga A, Genovese A, Veronesi L, Pasquarella C, et al. The use of onabotulinum toxin a $\left(\right.$ Botox $\left.^{\circledR}\right)$ in the treatment of chronic migraine at the Parma Headache Centre: a prospective observational study. Neurological Sciences. 2016; 37: 1127-1131.

[32] Janis JE, Barker JC, Palettas M. Targeted Peripheral Nervedirected Onabotulinumtoxin A Injection for Effective Long- 
term Therapy for Migraine Headache. Plastic and Reconstructive Surgery. Global Open. 2017; 5: e1270.

[33] Janis JE, Dhanik A, Howard JH. Validation of the peripheral trigger point theory of migraine headaches: single-surgeon experience using botulinum toxin and surgical decompression. Plastic and Reconstructive Surgery. 2011; 128: 123-131.

[34] Schoenbrunner AR, Khansa I, Janis JE. Cost-Effectiveness of Long-Term, Targeted OnabotulinumtoxinA versus Peripheral Trigger Site Deactivation Surgery for the Treatment of Refractory Migraine Headaches. Plastic \& Reconstructive Surgery. 2020; 145: 401e-406e.

[35] Batty AJ, Hansen RN, Bloudek LM, Varon SF, Hayward EJ, Pennington $\mathrm{BW}$, et al. The cost-effectiveness of onabotulinumtoxin A for the prophylaxis of headache in adults with chronic migraine in the UK. Journal of Medical Economics. 2013; 16: 877-887.

[36] Kollewe K, Gaul C, Gendolla A, Sommer K. Real-life use of onabotulinumtoxinA reduces healthcare resource utilization in individuals with chronic migraine: the REPOSE study. The Journal of Headache and Pain. 2021; 22: 50.

[37] Hansson-Hedblom A, Axelsson I, Jacobson L, Tedroff J, Borgström F. Economic consequences of migraine in Sweden and implications for the cost-effectiveness of onabotulinumtoxinA (Botox) for chronic migraine in Sweden and Norway. The Journal of Headache and Pain. 2020; 21: 99.

[38] Torres-Ferrus M, Gallardo VJ, Alpuente A, Pozo-Rosich P. Influence of headache pain intensity and frequency on migrainerelated disability in chronic migraine patients treated with OnabotulinumtoxinA. The Journal of Headache and Pain. 2020; 21: 88.

[39] Ornello R, Guerzoni S, Baraldi C, Evangelista L, Frattale I, Marini $\mathrm{C}$, et al. Sustained response to onabotulinumtoxin a in patients with chronic migraine: real-life data. The Journal of Headache and Pain. 2020; 21: 40.

[40] Young WB, Ivan Lopez J, Rothrock JF, Orejudos A, Manack Adams A, Lipton RB, et al. Effects of onabotulinumtoxinA treatment in chronic migraine patients with and without daily headache at baseline: results from the COMPEL Study. The Journal of Headache and Pain. 2019; 20: 12.

[41] Young WB, Ivan Lopez J, Rothrock JF, Orejudos A, Manack Adams A, Lipton RB, et al. Effects of onabotulinumtoxinA treatment in patients with and without allodynia: results of the COMPEL study. The Journal of Headache and Pain. 2019; 20: 10.

[42] Silberstein SD, Diener H, Dodick DW, Manack Adams A, DeGryse RE, Lipton RB. The Impact of OnabotulinumtoxinA vs. Placebo on Efficacy Outcomes in Headache Day Responder and Nonresponder Patients with Chronic Migraine. Pain and Therapy. 2020; 9: 695-707.

[43] Diener H, Dodick DW, Lipton RB, Manack Adams A, DeGryse RE, Silberstein SD. Benefits beyond Headache Days with OnabotulinumtoxinA Treatment: a Pooled PREEMPT Analysis. Pain and Therapy. 2020; 9: 683-694.

[44] Schulman E, McGeeney BE. Current concepts in refractory migraine. Current Treatment Options in Neurology. 2013; 15: 4055.

[45] Silberstein SD, Blumenfeld AM, Cady RK, Turner IM, Lipton RB, Diener $\mathrm{H}$, et al. OnabotulinumtoxinA for treatment of chronic migraine: PREEMPT 24-week pooled subgroup analysis of patients who had acute headache medication overuse at baseline. Journal of the Neurological Sciences. 2013; 331: 48-56.

[46] Blumenfeld AM, Patel AT, Turner IM, Mullin KB, Manack Adams A, Rothrock JF. Patient-Reported Outcomes from a 1-Year, RealWorld, Head-to-Head Comparison of OnabotulinumtoxinA and Topiramate for Headache Prevention in Adults with Chronic Migraine. Journal of Primary Care \& Community Health. 2020; 11: 2150132720959936

[47] Rothrock JF, Adams AM, Lipton RB, Silberstein SD, Jo E, Zhao $\mathrm{X}$, et al. FORWARD Study: Evaluating the Comparative Effectiveness of OnabotulinumtoxinA and Topiramate for Headache Prevention in Adults with Chronic Migraine. Headache. 2019; 59: 1700-1713.
[48] Blumenfeld AM, Aurora SK, Laranjo K, Papapetropoulos S. Unmet clinical needs in chronic migraine: Rationale for study and design of COMPEL, an open-label, multicenter study of the longterm efficacy, safety, and tolerability of onabotulinumtoxinA for headache prophylaxis in adults with chronic migraine. BMC Neurology. 2015; 15: 100.

[49] Boudreau GP, Grosberg BM, McAllister PJ, Lipton RB, Buse DC. Prophylactic onabotulinumtoxinA in patients with chronic migraine and comorbid depression: an open-label, multicenter, pilot study of efficacy, safety and effect on headache-related disability, depression, and anxiety. International Journal of General Medicine. 2015; 8: 79-86.

[50] d'Onofrio F, de Falco A, Costanzo A, Spitaleri D, Casucci G, Raimo $\mathrm{S}$. Impulse control disorders in chronic migraine with medication overuse after onabotulinumtoxin A: a single-center prospective cohort study. Journal of Clinical Neuroscience. 2020; 80: $152-$ 155.

[51] Kim CC, Bogart MM, Wee SA, Burstein R, Arndt KA, Dover JS. Predicting migraine responsiveness to botulinum toxin type a injections. Archives of Dermatology. 2010; 146: 159-163.

[52] Kabbouche M, O'Brien H, Hershey AD. OnabotulinumtoxinA in Pediatric Chronic Daily Headache. Current Neurology and Neuroscience Reports. 2012; 12: 114-117.

[53] Wong H, Khalil M, Ahmed F. OnabotulinumtoxinA for chronic migraine during pregnancy: a real world experience on 45 patients. The Journal of Headache and Pain. 2020; 21: 129.

[54] Negro A, Curto M, Lionetto L, Martelletti P. A two years openlabel prospective study of OnabotulinumtoxinA 195 U in medication overuse headache: a real-world experience. The Journal of Headache and Pain. 2015; 17: 1.

[55] Negro A, Curto M, Lionetto L, Crialesi D, Martelletti P. Onabotulinumtoxin $\mathrm{A} 155 \mathrm{U}$ in medication overuse headache: a two years prospective study. SpringerPlus. 2015; 4: 826.

[56] Sandrini G, Perrotta A, Tassorelli C, Torelli P, Brighina F, Sances $\mathrm{G}$, et al. Botulinum toxin type-a in the prophylactic treatment of medication-overuse headache: a multicenter, double-blind, randomized, placebo-controlled, parallel group study. The Journal of Headache and Pain. 2011; 12: 427-433.

[57] Guerzoni S, Pellesi L, Baraldi C, Cainazzo MM, Negro A, Martelletti $P$, et al. Long-term Treatment Benefits and Prolonged Efficacy of OnabotulinumtoxinA in Patients Affected by Chronic Migraine and Medication Overuse Headache over 3 Years of Therapy. Frontiers in Neurology. 2017; 8: 586.

[58] Matharu M, Halker R, Pozo-Rosich P, DeGryse R, Manack Adams A, Aurora SK. The impact of onabotulinumtoxinA on severe headache days: PREEMPT 56-week pooled analysis. The Journal of Headache and Pain. 2017; 18: 78.

[59] Binder WJ, Brin MF, Blitzer A, Schoenrock LD, Pogoda JM. Botulinum toxin type a (BOTOX) for treatment of migraine headaches: an open-label study. Otolaryngology-Head and Neck Surgery. 2000; 123: 669-676.

[60] Silberstein S, Mathew N, Saper J, Jenkins S. Botulinum Toxin Type a as a Migraine Preventive Treatment. Headache. 2000; 40: 445-450.

[61] Aurora SK, Gawel M, Brandes JL, Pokta S, Vandenburgh AM. Botulinum toxin type a prophylactic treatment of episodic migraine: a randomized, double-blind, placebo-controlled exploratory study. Headache. 2007; 47: 486-499.

[62] Finkel AG. Botulinum toxin and the treatment of headache: a clinical review. Toxicon. 2015; 107: 114-119.

[63] Shuhendler AJ, Lee S, Siu M, Ondovcik S, Lam K, Alabdullatif A, et al. Efficacy of Botulinum Toxin Type a for the Prophylaxis of Episodic Migraine Headaches: a Meta-analysis of Randomized, Double-Blind, Placebo-Controlled Trials. Pharmacotherapy. 2009; 29: 784-791.

[64] Luvisetto S, Gazerani P, Cianchetti C, Pavone F. Botulinum Toxin Type a as a Therapeutic Agent against Headache and Related Disorders. Toxins. 2015; 7: 3818-3844.

[65] Simpson DM, Hallett M, Ashman EJ, Comella CL, Green MW, 
Gronseth GS, et al. Practice guideline update summary: Botulinum neurotoxin for the treatment of blepharospasm, cervical dystonia, adult spasticity, and headache. Neurology. 2016; 86: 1818-1826.

[66] Elkind AH, O'Carroll P, Blumenfeld A, DeGryse R, Dimitrova R. A series of three sequential, randomized, controlled studies of repeated treatments with botulinum toxin type a for migraine prophylaxis. The Journal of Pain. 2006; 7: 688-696.

[67] Relja M, Poole AC, Schoenen J, Pascual J, Lei X, Thompson C. A multicentre, double-blind, randomized, placebo-controlled, parallel group study of multiple treatments of botulinum toxin type a (BoNTA) for the prophylaxis of episodic migraine headaches. Cephalalgia. 2007; 27: 492-503.

[68] Wieckiewicz M, Grychowska N, Zietek M, Wieckiewicz G, Smardz J. Evidence to Use Botulinum Toxin Injections in Tension-Type Headache Management: a Systematic Review. Toxins. 2017; 9: 370.

[69] Pihut M, Ferendiuk E, Szewczyk M, Kasprzyk K, Wieckiewicz M. The efficiency of botulinum toxin type a for the treatment of masseter muscle pain in patients with temporomandibular joint dysfunction and tension-type headache. The Journal of Headache and Pain. 2016; 17: 29.

[70] Harden RN, Cottrill J, Gagnon CM, Smitherman TA, Weinland SR, Tann B, et al. Botulinum Toxin a in the Treatment of Chronic Tension-Type Headache with Cervical Myofascial Trigger Points: a Randomized, Double-Blind, Placebo-Controlled Pilot Study. Headache. 2009; 49: 732-743.

[71] Mizuma A, Nagata E, Yasuda T, Kouchi M, Nakayama T, Honma $\mathrm{K}$, et al. Botulinum toxin a is effective to treat tension-type headache caused by hemifacial spasm. Journal of Clinical Neuroscience. 2017; 44: 284-288.

[72] Spears RC. Efficacy of botulinum toxin type a in new daily persistent headache. The Journal of Headache and Pain. 2008; 9: 405406.

[73] Ali A, Kriegler J, Tepper S, Vij B. New Daily Persistent Headache and OnabotulinumtoxinA Therapy. Clinical Neuropharmacology. 2019; 42: 1-3.

[74] Freund B, Kotchetkov I, Rao A. The Efficacy of Botulinum Toxin in Cluster Headache: a Systematic Review. Journal of Oral \& Facial Pain and Headache. 2020; 34: 129-134.

[75] Lampl C, Rudolph M, Bräutigam E. OnabotulinumtoxinA in the treatment of refractory chronic cluster headache. The Journal of Headache and Pain. 2018; 19: 45.

[76] Bratbak DF, Nordgård S, Stovner LJ, Linde M, Folvik M, Bugten $\mathrm{V}$, et al. Pilot study of sphenopalatine injection of onabotulinumtoxinA for the treatment of intractable chronic cluster headache. Cephalalgia. 2016; 36: 503-509.

[77] Sostak P, Krause P, Förderreuther S, Reinisch V, Straube A. Botulinum toxin type-a therapy in cluster headache: an open study. The Journal of Headache and Pain. 2007; 8: 236-241.
[78] Bagheri A, Mohammadi M, Harooni G, Khosravifard K, Feizi M, Yazdani S. Cluster Headache Associated with Secondary Unilateral Blepharospasm: a Case Report and Review of the Literature. Journal of Ophthalmic \& Vision Research. 2017; 12: 225-227.

[79] Karadaş O, Oztürk B, Ulaș UH, Kütükçü Y, Odabaşı Z. The Efficacy of Botulinum Toxin in Patients with Cervicogenic Headache: a Placebo-Controlled Clinical Trial. Balkan Medical Journal. 2012; 29: 184-187.

[80] Hobson DE, Gladish DF. Botulinum toxin injection for cervicogenic headache. Headache. 1997; 37: 253-255.

[81] Padberg M, de Bruijn SFTM, Tavy DLJ. Neck pain in chronic whiplash syndrome treated with botulinum toxin. a double-blind, placebo-controlled clinical trial. Journal of Neurology. 2007; 254: 290-295.

[82] Carroll A, Barnes M, Comiskey C. A prospective randomized controlled study of the role of botulinum toxin in whiplash-associated disorder. Clinical Rehabilitation. 2008; 22: 513-519.

[83] Zirovich MD, Pangarkar SS, Manh C, Chen L, Vangala S, Elashoff DA, et al. Botulinum Toxin Type a for the Treatment of Posttraumatic Headache: a Randomized, Placebo-Controlled, Crossover Study. Military Medicine. 2021; 186: 493-499.

[84] Yerry JA, Kuehn D, Finkel AG. Onabotulinum Toxin a for the Treatment of Headache in Service Members with a History of Mild Traumatic Brain Injury: a Cohort Study. Headache. 2015; 55: 395406.

[85] Lippert-Grüner M. Botulinum toxin in the treatment of posttraumatic headache - case study. Neurologia i Neurochirurgia Polska. 2012; 46: 591-594.

[86] Ivanhoe CB, Lai JM, Francisco GE. Bruxism after brain injury: successful treatment with botulinum toxin-A. Archives of Physical Medicine and Rehabilitation. 1997; 78: 1272-1273.

[87] MacKenzie HM, Teasell R, Miller TA, Sequeira K. Peri-Incisional Botulinum Toxin for Chronic Postcraniotomy Headache after Traumatic Brain Injury: a Case Series. PM and R. 2015; 7: 785788.

[88] Ranoux D, Martiné G, Espagne G, Salle H, Caire F. Delayed-onset post-craniotomy headache responsive to botulinum toxin a: a case series. Acta Neurochirurgica. 2017; 159: 1375-1378.

[89] Mathew PG, Cutrer FM. Injecting under pressure: the pain of low CSF pressure headache responsive to botulinum toxin injections. Current Neurology and Neuroscience Reports. 2014; 14: 477.

[90] García-Azorín D, Trigo-López J, Sierra Á, Blanco-García L, Martínez-Pías E, Martínez B, et al. Observational, open-label, non-randomized study on the efficacy of onabotulinumtoxinA in the treatment of nummular headache: the pre-numabot study. Cephalalgia. 2019; 39: 1818-1826.

[91] Nahabet E, Janis JE, Guyuron B. Neurotoxins: Expanding Uses of Neuromodulators in Medicine-Headache. Plastic and Reconstructive Surgery. 2015; 136: 104S-110S. 